\title{
Flipping an Engineering Thermodynamics Course to Improve Student Self- Efficacy
}

\section{Dr. Karim Altaii, James Madison University}

Dr. Altaii holds a Ph.D. in mechanical engineering, and received his doctorate from The City University of New York. He is a registered Professional Engineer. He holds five patents in solar energy applications and in irrigation system. He is the director of two international summer programs. He is the Co-Director of the Advanced Thermal-Fluids laboratory. His primary interests are in renewable energy applications, fluid-thermal sciences, and international education.

\section{Dr. Colin J. Reagle, George Mason University}

Colin Reagle joined the Volgenau School of Engineering at George Mason University in 2014, specializing in the area of thermal fluid flows and sustainable energy systems. He brings his extensive background in the subjects to Mason as a boon to the growing mechanical engineering program. He has also taught and conducted postdoctoral research at Virginia Tech including research projects for Solar Turbines, Siemens, Pratt and Whitney, Rolls-Royce, and Honeywell. Reagle has R\&D experience as a researcher for Techsburg, a small engineering services company in Christiansburg, Virginia.

His primary focus at Mason has growing the Mechanical Engineering undergraduate program through teaching in his areas of expertise and service to department and VSE. Reagle has a passion for working with students and enabling them to pursue their goals. He is involved in multiple student centric efforts including developing a small scale, anaerobic digester to harvest energy from food waste in urban and suburban environments; a multidisciplinary entrepreneurship program encouraging students to develop ideas from the classroom; converting a required course in the ME curriculum to use Open Educational Resources; a cross institutional effort to flip and improve a required thermodynamics course; and a multidisciplinary research effort to assess urban hydroelectric microturbines as a solution to joint energy and water challenges.

\section{Dr. Mary K. Handley, James Madison University}

Dr. Handley received a Ph.D. in Plant Pathology from the University of California-Davis. She has been a faculty member in the Integrated Science and Technology Department at James Madison University since 1998, teaching courses in Environmental Science and Chemistry. She was the ISAT program assessment coordinator for 14 years. Dr. Handley's primary interests are in program assessment, environmental education, and sustainable agriculture. 


\title{
Flipping an Engineering Thermodynamics Course to Improve Student Self-Efficacy
}

\begin{abstract}
Thermodynamics is well documented as a difficult course in the engineering and technology curricula that require it. The flipped lecture format has been similarly documented to improve student-teacher interaction and student engagement. This work attempts to address whether flipping a difficult, demanding thermodynamics course improves student self-efficacy.

Student surveys were conducted in multiple sections of a thermodynamics course over two years to evaluate student perceptions of the flipped course format. Students had positive perceptions about how class time was used in the flipped lecture style which was expected based on previous literature. Nearly all of the respondents agreed that using class time for discussion and problemsolving was very useful. No specific topic was singled out as unsuitable for the flip format; however several comments suggest that highly conceptual topics or topics that may be difficult to understand without examples are not suited for the flip format. Many students commented that the video lectures allowed them to be more prepared when they went to class and more actively engaged with class material. Most students also agree that they are confident in their ability to solve problems and apply their knowledge to new problems introduced in the course and in their ability to solve related problems in their future academic and professional endeavors. A majority of students also agreed that the course helped them to develop their own questions about the material and become more independent learners. These responses strongly support the use of the flipped class format for teaching technical courses and to improve self-efficacy.
\end{abstract}

The methodology of flipping the course, lessons learned and the instructor's observations are also presented here. Developing flipped course materials is very time-consuming. Our results document the positive benefits of this teaching style for both students and instructors.

\section{Introduction}

In a flipped classroom, students are asked to prepare outside the class by reading or watching videos, then learn actively in the classroom with the majority of the time now devoted to problem solving, rather than content delivery. The idea of students teaching themselves new material before class is not a new one but the explosion of flipped classrooms in recent years, buoyed by better technology and tools for creating video content, has led to many new topics being explored for potential flipping, inversion, or blended learning. Research exists on the reported benefits and methodology behind flipping a class and a majority of the reviewed research done by O'Flaherty and Philips (2015) and Bishop and Verleger (2013) focuses on qualitative student surveys as a trial implementation.

One area where there is limited research on the technique is with engineering technical courses. These technical courses appear to be ideal candidates for flipping, with their heavy emphasis on both the introduction of new content and problem solving. Wessling and Roller (2016) described students' perceptions, reactions and adjustments made to flipping a heat transfer course. Wagner et. al. (2013) analyzed the flipped classroom as a technique to increase content retention in an electronic systems engineering course by interspersing traditional and flipped lectures throughout 
a semester. Qualitative surveys showed that students preferred and found useful the flipped lectures coupled with strategically designed in-class activities.

Another common research question involves student performance in flipped classrooms. Bishop and Verleger (2013) flipped a numerical methods course for engineers and performed a qualitative analysis of results in a controlled study with objective measures. The results presented by Bishop (2013) showed no significant differences on quiz and exam scores between the flipped and traditional classroom. Lape et. al. (2014) also performed a controlled, objective analysis of an undergraduate chemical and thermal processes course and found no difference on assessments between flipped and traditional classrooms. Mason et. al. (2013) compared a traditional and flipped control systems engineering course for content coverage, student performance, and student perceptions. They found similar or higher levels of student performance and perception in the flipped classroom. With these results suggesting that there is no harm done in flipping the course, what are the benefits of flipping a course?

One of the possible benefits is self-efficacy. Bandura (1997) defines perceived self-efficacy as: "...beliefs in one's capabilities to organize and execute the courses of action required to produce given attainments." Higher levels of self-efficacy lead to greater accomplishment. Again, from Bandura:

"[Self-efficacy] influences the courses of action people choose to pursue, how much effort they put forth in given endeavors, how long they will persevere in the face of obstacles and failures, their resilience to adversity, whether there thought patterns are self-hindering or self-aiding, how much stress and depression they experience in coping with taxing environmental demands, and the level of accomplishment they realize."

One of the major reasons that students leave STEM fields is loss of academic self-confidence historically documented by Seymour and Hewitt (1997). In addition to self-confidence, selfefficacy - a belief in one's ability to accomplish desired tasks - is an important part of student persistence. Our work looks at the use of a flipped lecture format to improve student self-efficacy in a difficult thermodynamics course.

\section{Instructional Context}

Abbeysekera and Dawson (2015) cite the need for high-level uniform definitions of the flipped classroom to facilitate comparisons between studies. For that reason, we also describe our flipped course design and structure. This description has been published in Altaii and Pierrakos (2017).

\section{Course Name and Description}

This flipped course - Energy Fundamentals (ISAT 310) — covers the integration of fundamental concepts from physics, chemistry, mathematics, and engineering within the context of energy applications. Principles governing energy transformations, transport and conversion, including laws of thermodynamics and thermal-science are all covered. The course is a junior-level, required course in the Energy Sector (one of six strategic sectors) in the Integrated Science and Technology (ISAT) program at James Madison University. The course is considered one of the hardest in the curriculum and enrolls about 50 students each year. 


\section{Course Learning Goals}

The five overarching learning goals are to enable students to:

1. Gain a thorough understanding of the basic definitions, concepts and principles of thermodynamics.

2. Analyze thermodynamic processes and cycles within the conceptual frameworks of the First and Second Laws.

3. Apply the basic concepts of thermodynamics to the solution of practical problems (e.g., power generation and transformation).

4. Understand how different forms of energy differ in quality and how that quality of energy affects the efficiency of energy-consuming devices;

5. Develop an orderly approach to problem solving.

\section{Models and Theories Used to Guide the Flipping}

Having taught a few versions of this course with a variety of students using a more traditional lecture-based pedagogical model for 25 years, it was not until recently that the course was flipped. Although learning still took place in the more traditional lecture-based course, it was evident year after year that students were not coming prepared for class, they were not reading course content, and thus class time was spent mostly on lecturing with some discussion and limited interaction. Outside of class, students were challenged to solve problems on their own and their understanding of course content was not improving. The initial rationale for flipping was three-fold:

- For students to take ownership of their learning and to change the mentality that the ownership belonged to the instructors.

- For students to learn the content more deeply and not superficially, as well as for students to become better problem solvers.

- With increasing teaching loads, the cognitive load on instructors to have multiple courses and multiple sections of a course also increased. Lecturing one course after another became a challenge and not as enjoyable or productive.

In flipping the course, it was important for students to ease into the flipped classroom. Thus, the course was broken into three key parts. In order for the students to begin to form a relationship with their instructor and his/her teaching style, the first four weeks followed the more traditional lecture-based pedagogical model. The first four weeks covered material such as basic thermodynamics definitions, use of thermodynamics property tables, heat and work and skills for problem solving.

The next seven weeks, representing the more applied knowledge (conservation of mass, first and second laws of thermodynamics), were flipped and involved pre-recorded videos and selfreflection guides, which we call Flip Lecture Sheets (FLS). FLS reflections had to be completed before class and were meant as a mechanism to ensure students actively watched the videos. The last three weeks (thermodynamic cycles) were focused on application and the course project. Pre-recorded videos were not used in this part of the course because the focus is on integrating the knowledge gained throughout the course and applying that knowledge to solve more complex problems. The culminating project was a key part of the last three weeks. From start to end, students were given progressively greater ownership and responsibility in applying knowledge. 
A theoretical framework guiding this approach is Cognitive Apprenticeship Theory (CAT) introduced by Collins et al. (1991) and Rogoff (1991). As a social cognitive theory, CAT posits that students learn from experts by observation, imitation, and modeling. The instructor(s) serve as coaches to bring tacit processes out in the open. In flipping the course described herein, students spent more time actively observing and learning from the instructor than was possible in the traditional lecture format. Coaching was more targeted and problem solving became an exploration where strategies were learned, reflection was built in with student peers working together, and informed inquiry prior to coming to class enabled scaffolding.

\section{Structure of the Flipped Course}

During the flipped portion of the course, key activities took place before class, during class, and after class. Before class and at least one week in advance, lecture notes were given to students, pre-recorded video lectures were posted, and the FLS was also given. Students were expected to watch the videos ahead of class. At the beginning of class, students submitted a hard copy of the FLS, which included (a) their questions about the material covered in the video, (b) a signature acknowledging that they watched the video, and (c) feedback to continuously improve the prerecorded video. FLS submission counted as part of the homework grade. During class, approximately one-third of the time was focused on answering and discussing the questions submitted on the FLS. This process involved identifying common themes and misconceptions. A second third of the class focused on the instructor solving problems on the board and asking questions of the students. In the last third of the class, students worked individually or in small groups to solve additional problems or even to start the homework. Out-of-class activities involved watching pre-recorded videos, completing FLS sheets, and completing homework.

\section{Methodology}

This study involved students from five sections of the Thermodynamics course described above, delivered in Fall 2015 and Fall 2016. The same instructor taught all five classes; all videos and other class materials were the same in both years. The data consist of pre and post survey results, and instructor observations about the class. In addition to the 2015 and 2016 survey data and observations, average final grades for the course were calculated over six years (three years in traditional lecture format and three years in the flipped format.) It should be noted that a survey was not conducted during the $1^{\text {st }}$ year of flipping the class.

\section{Participants}

Total enrollment in all sections that were surveyed was 87 students; $78 \%$ male and $22 \%$ female. They were all ISAT majors with junior level standing. This was a required course for degree completion for $80 \%$ of the students taking the course. About $60 \%$ of the students had prior experience with a flipped lecture class (mostly with the same instructor in a lower-level class). In an independent samples T-test, grouped by whether or not a student had previously taken a flipped lecture course, there were no significant differences between groups for any of the survey items ( $p$ values from 0.159 to 0.948 .) Similarly, when grouped by semester, there were no significant differences between semesters for any of the survey items ( $p$ values from 0.232 to 1.000.) All further analysis was conducted on the entire population. 


\section{Procedure and Instruments}

Two anonymous surveys were conducted in five sections of the ISAT 310 thermodynamics course during the Fall 2015 and 2016 semesters. The first survey was given during the second week of the semester and the second was given in the last week of the semester. Students were sent an email requesting that they complete the survey and a secure link to the survey. The emails were followed up with announcements in class. The first survey asked students their perception of the class difficulty. The survey items are presented in Table 1 . There were 86 valid responses out of a total enrollment of 87 (99\% response rate).

The end-of-course survey was delivered in the same way. This survey asked about students' prior experience in flipped classes, how frequently they completed the video assignments, their perception of the class difficulty and format, and the impact of the class on several self-efficacy measures. The items are in Table 2. Likert scale items were on a 5 point scale. Five responses were removed from the data set: two duplicates and three incomplete responses (incomplete was defined as a response with more than three-fourths of items unanswered.) This left 76 valid responses (response rate $87 \%$.)

Table 1: Course difficulty items on both surveys

Do you agree that ISAT 310 is one of the hardest courses in the ISAT major?

Which of the following contributes to your perception of the ISAT 310 course?

- The course is demanding, with many homework assignments, quizzes, and exams.

- There is a large amount of material covered in the course (many equations, parameters, constants, laws)

- The material is difficult to understand

- The instructor has high expectations of the students.

- Other reason (please specify)

Table 2: End of the course survey items.

1. Have you taken a "flipped" lecture class before this semester?

2. I watched the videos and came prepared for class:

(Follow-up) Please comment on how your performance in class was impacted when you didn't watch the videos before you came to class.

3. The course helped me to become an independent learner, finding answers to questions using course materials (videos, textbook, handouts, etc.) as opposed to asking fellow students or instructors.

4. The flipped lecture format helped me to develop my own questions about the material.

5. I feel confident I can solve problems presented during this course.

6. I feel confident I could apply what I have learned in this course to a new problem posed by a future employer.

7. Spending time in class to discuss the information presented in the videos was:

8. Spending time In class to solve sample problems was:

9. The flipped lecture format allowed me to develop a deep understanding about the topics covered in this course.

10. All topics in the course were well suited for the flipped lecture format.

(Follow-up) Which topics were not well suited for the flipped lecture format? 


\section{Survey Analysis}

As indicated above, all survey responses were combined for analysis. The surveys included several Likert style items related to the course difficulty, flipped lecture format and perceived self-efficacy. Chi-square and independent samples T-tests were used to compare results between items that were on both surveys. Frequency data and visual examination of trends were used to evaluate self-efficacy and class format items. Open-ended responses were indexed for keywords and phrases; these were evaluated for common themes and the number of responses within each theme area was totaled. The open-ended items were: "Please comment about how your performance in class was impacted when you watched the videos before you came to class.", "Please comment on how your performance in class was impacted when you didn't watch the videos before you came to class.", "Which topics were not well suited for the flipped lecture format?", and "Please provide any additional thoughts or comments about your experience in this flipped lecture class.”

\section{Student Grades}

This course was taught in traditional lecture format from 2011-2013 and in flipped format from 2014-2016, all with the same instructor, course content, general teaching style and rigor. In each year, student learning assessment included homework, exams, quizzes, and a course project. These types of assessments were similar across all years. Average final grades were calculated for these six cohorts of students and the mean and standard deviation for each course format were compared.

\section{Results and Discussion}

The results are grouped according to the responses they were designed to elicit. Validating student perceptions of the difficulty of the course and the reasons for this perceived difficulty; Determining student participation in watching the flipped lectures and their responses to how it affected their in class performance; The use of class time when the flipped videos were watched outside of class; The suitability of different topics for flipped lectures and the effect on the pace of learning; and determining student confidence on problem solving after taking a flipped class and specific aspects of self-efficacy.

\section{Student Perception of Course Difficulty}

One of the motivations for this work was to study whether flipping a difficult course can improve student self-efficacy. To validate that this is indeed a difficult course for students, pre and post surveys captured their perceptions of the course and the reasons behind them. Three-fourths of the students in the pre survey and over $90 \%$ in the post survey agree with or strongly agree that the course is one of the most difficult courses in the ISAT curriculum (Figure 1). This perception is also evidenced in the literature (Ugursal and Cruickshank, 2014). 


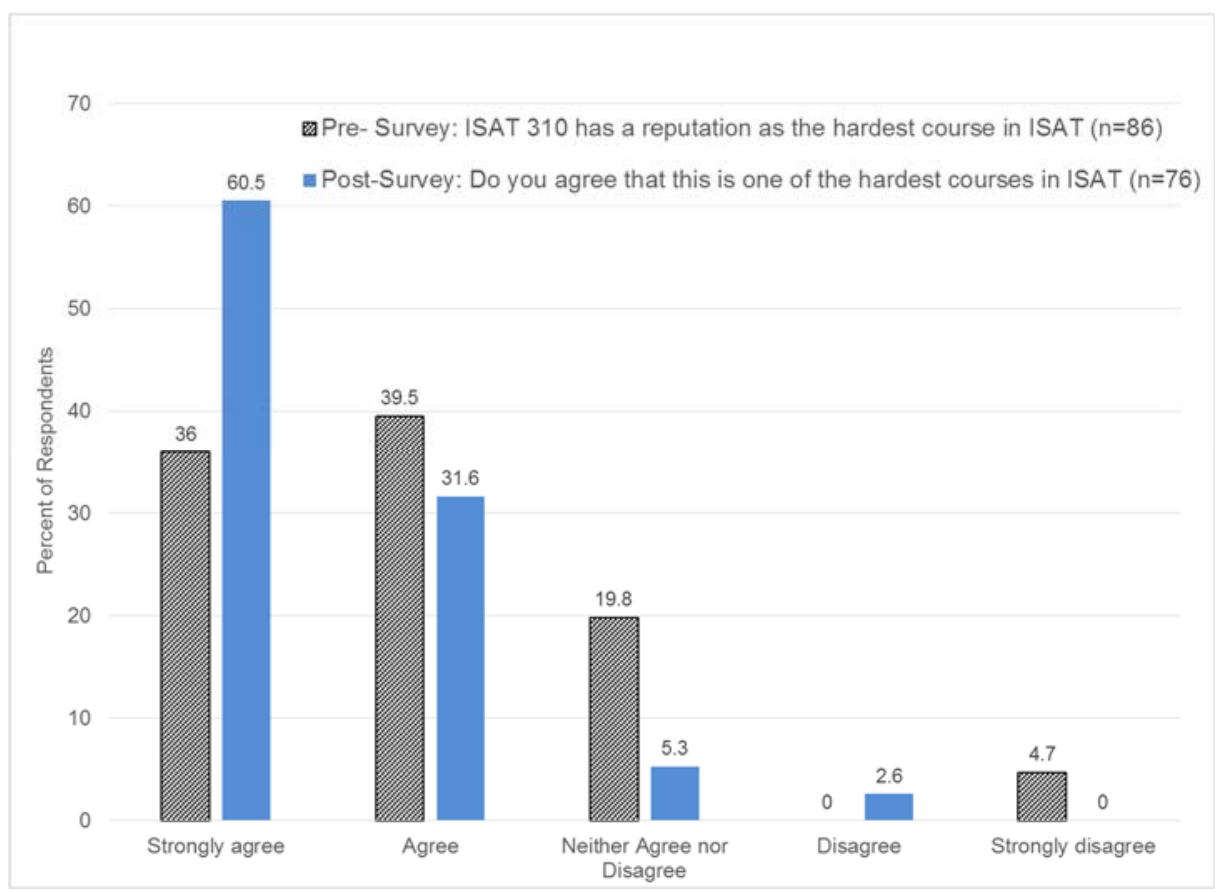

Figure 1. Survey responses regarding difficulty of course

But the more interesting question is why the course has the reputation for being difficult and whether that changes after completing the course. The survey included four possible reasons for the course's reputation (Table 3.) For three of the four reasons (the course has many assignments, homeworks, and exams; there is a large amount of material; and the instructor has high expectations), there was a highly significant difference between pre-survey and post-survey responses $(\mathrm{p}<.001)$ in chi square tests (Table 3$)$ All three showed much higher agreement in the end of course survey. These statements all describe attributes of the course requirements and structure - elements that are controlled by the instructors. The proportion of students who agree with the fourth item about the course's reputation - the perception that the material is difficult to understand showed no significant difference between the pre and post surveys. This is a statement about the course content rather than about instructors' requirements.

Table 3. Which of the following contributes to your perception of the ISAT 310 course?

\begin{tabular}{|l|l|l|l|}
\hline Reason & $\begin{array}{l}\text { Pre-survey } \\
(\mathbf{n = 8 6 )}\end{array}$ & $\begin{array}{l}\text { Post-survey } \\
(\mathbf{n = 7 6 )}\end{array}$ & $\boldsymbol{X}^{2}$ and $\boldsymbol{p}$ \\
\hline $\begin{array}{l}\text { The course is demanding, with many } \\
\text { assignments... }\end{array}$ & $62.8 \%$ & $93.4 \%$ & $\mathrm{X}^{2}=19.78, \mathrm{p}<0.001$ \\
\hline The course covers a lot of material & $65.1 \%$ & $90.8 \%$ & $\mathrm{X}^{2}=13.77, \mathrm{p}<0.001$ \\
\hline The instructor has high expectations & $57.0 \%$ & $88.2 \%$ & $\mathrm{X}^{2}=17.79, \mathrm{p}<0.001$ \\
\hline The material is difficult to understand & $69.8 \%$ & $65.8 \%$ & $\mathrm{X}^{2}=0.14, \mathrm{p}=0.355$ \\
\hline
\end{tabular}

\section{Student Participation}

The success of a flipped class is affected by student participation. Responses to the item: "I watched the videos and came prepared for class) indicate that most of the students $(85.5 \%$, Table 4) were regularly following instructions on how to learn in a flipped classroom by watching the videos and preparing questions for class time. This finding is supported by evidence from the 
FLS submitted during each class meeting.

Table 4. I watched the videos and came prepared for class:

\begin{tabular}{|l|c|c|}
\hline Response & n & \% \\
\hline All of the time & 28 & 36.8 \\
\hline Often & 37 & 48.7 \\
\hline Sometimes & 10 & 13.2 \\
\hline Rarely & 1 & 1.3 \\
\hline Never & 0 & 0 \\
\hline
\end{tabular}

Two open-ended questions asked how performance in class was impacted when you watched (or didn't watch) the videos before you came to class. Table 5 summarizes these responses.

Table 5. Summary of the most frequent responses to the questions: "Please comment on how your performance in class was impacted when you watched the videos before you came to class" and "Please comment on how your performance in class was impacted when you didn't watch the videos before you came to class."

\begin{tabular}{|l|c|}
\hline Benefits when I watched the videos beforehand: & n \\
\hline $\begin{array}{l}\text { Before I went to class: felt more prepared; knew what to expect; had background } \\
\text { knowledge }\end{array}$ & 21 \\
\hline $\begin{array}{l}\text { When I was in class: could follow easily; actively engage; come up with initial } \\
\text { questions }\end{array}$ & 15 \\
\hline $\begin{array}{l}\text { Helped my learning because: repetition helped; could go at my own pace; pause to } \\
\text { find more information }\end{array}$ & 10 \\
\hline Problems that I had even when I watched the videos before class: & 10 \\
\hline Videos hard to follow; I was still confused & 4 \\
\hline $\begin{array}{l}\text { I don't know how to make my own questions; couldn't get answers to my } \\
\text { questions right away }\end{array}$ & 4 \\
\hline I prefer other learning formats (lecture, text) & 13 \\
\hline If I didn't watch I was: & \\
\hline Lost, behind, had no idea what was going on in class & \\
\hline
\end{tabular}

Many of the more positive responses to the flipped format referred to the pace of learning. As one student wrote: "I picked things up better in the videos because I could pause it, google my questions to see it explained a different way, and move on when I was ready" Another said: "I really enjoyed the flip lecture because it allowed me to work at my own pace and understand the material without being left behind." These students were using the video lectures effectively. These differences in approach and/or learning style are likely reasons for the mixed responses regarding the satisfaction with the class format. Results are shown below (Figure 2) 


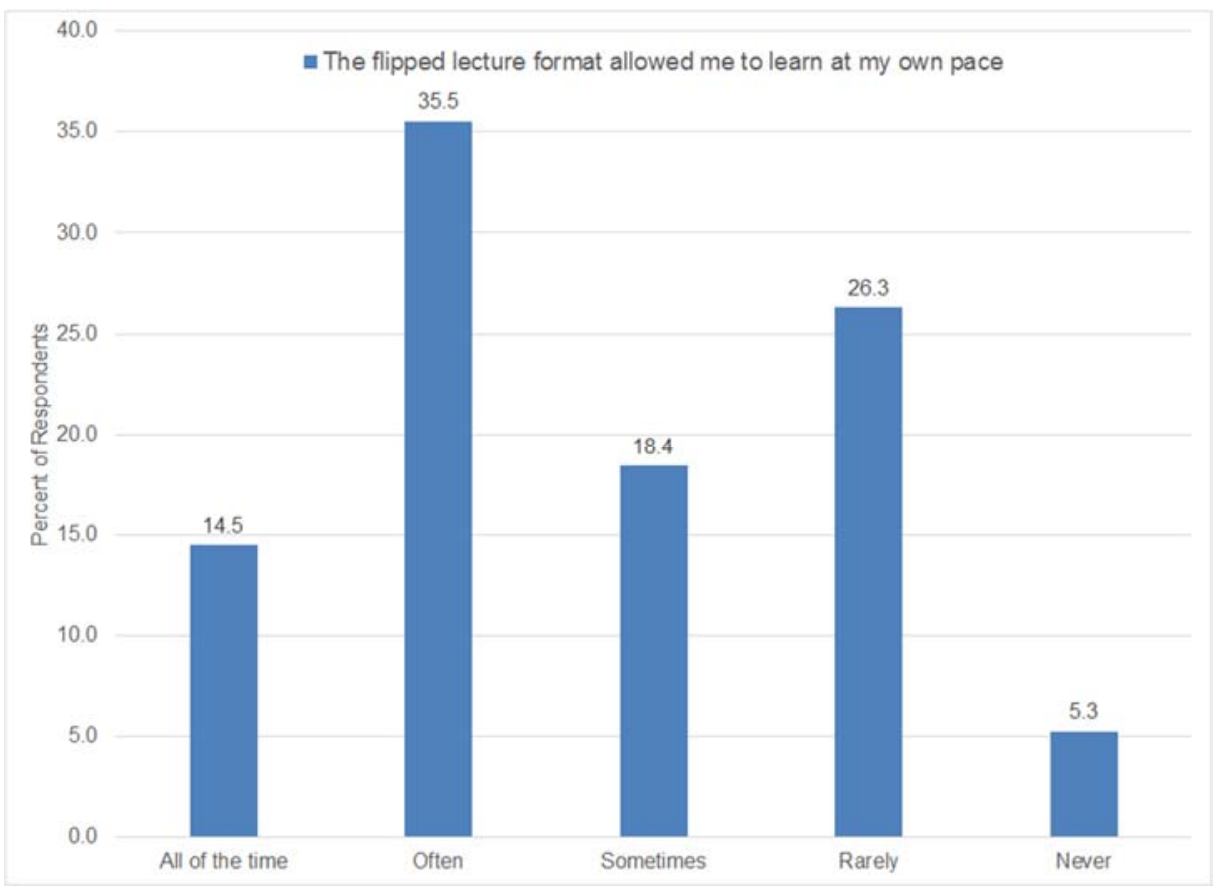

Figure 2. Pace of learning

\section{Use of Class Time}

Moving material outside of class time directly influences the availability of in-class time to focus on discussion of material and problem solving. Student response to the two items about the use of class time (Figure 3 ) indicate that they found spending time in class discussing information from the videos and solving problems was useful or very useful. The most positive response was in the use of class time to solve problems, which has anecdotally been a common request from students taking the course in a traditional format. Most students felt that using class time to solve problems was "very useful", while only $22 \%$ said that discussing information in the videos was "very useful." One student wrote "... the flip lecture model was so successful because class time was dedicated to answering questions and solving problems. Being able to work on practice problems in an atmosphere where your peers and professor could help you get to the correct answer was extremely helpful." 


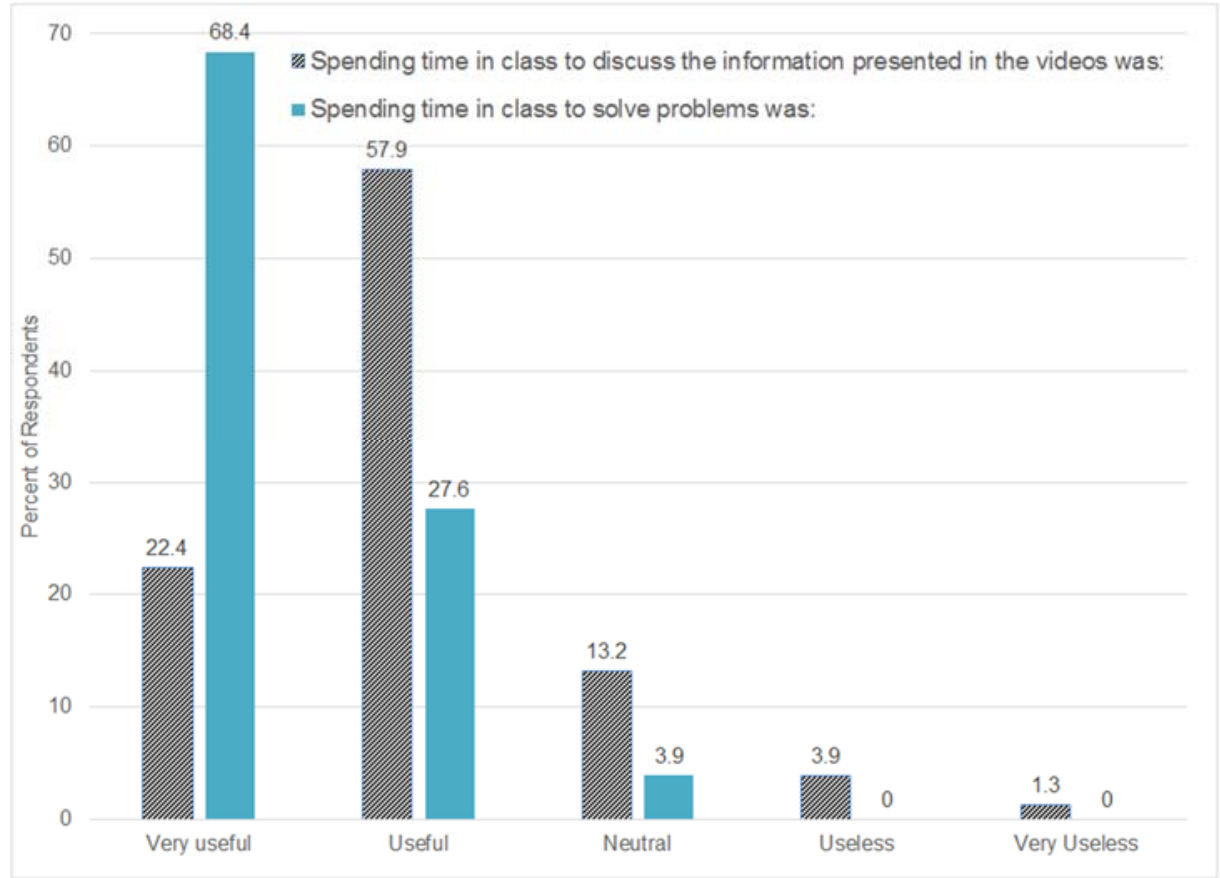

Figure 3. Survey responses to the Use of Class Time

\section{Suitability of Flipped Lecture to Thermodynamics Topics and Pace of Learning}

Responses to one of the items that related directly to the flipped lectures was mixed. Only about half of students agreed or strongly agreed with the statements: "All topics in the course were well suited for the flipped lecture format" (Figure 4)

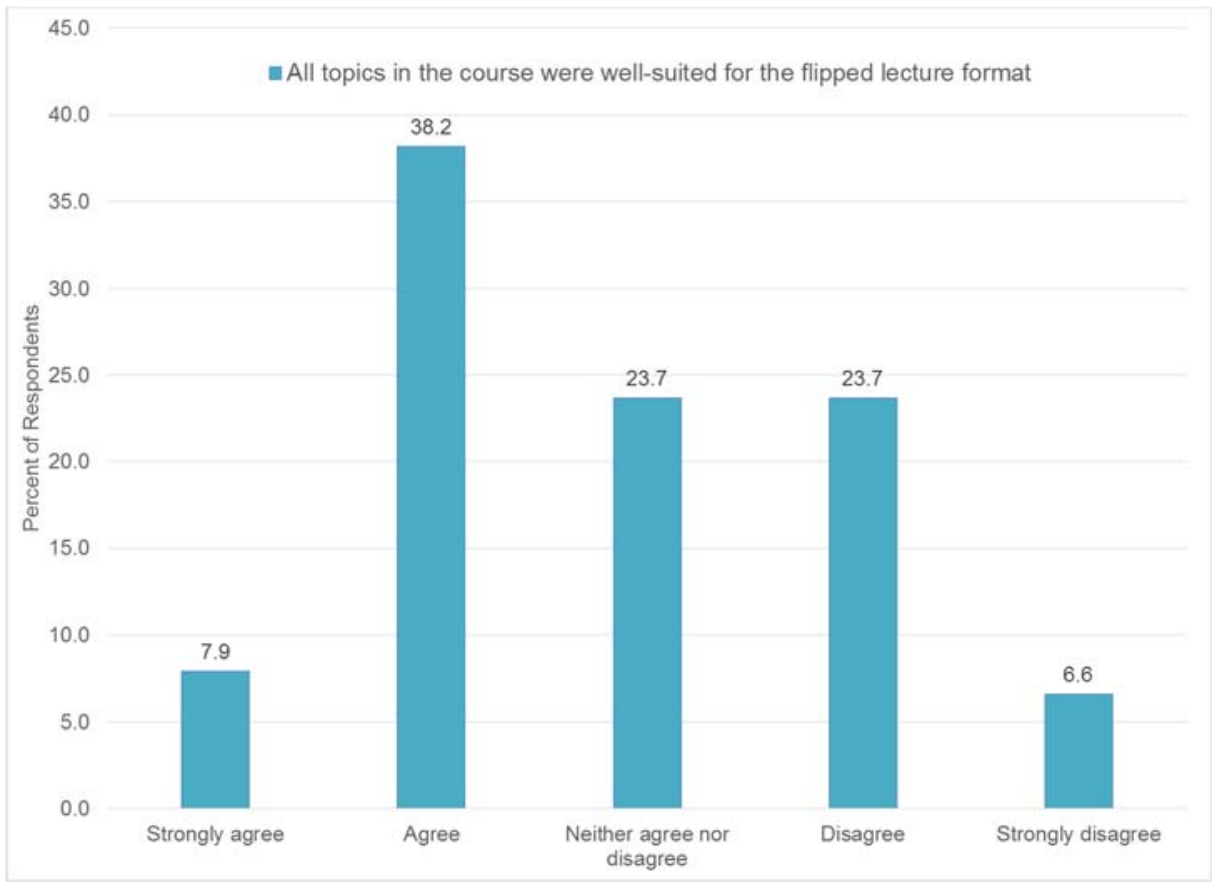

Figure 4. Survey responses to the Flipped lecture format 
Open-ended responses provide some insight into student perceptions of which course topics are well suited to the flipped format. Many of the comments focused on topics that had large numbers of associated equations or derivations, such as entropy. One student responded "I believe entropy could have been better explained in lectures rather than the flip lecture format. There were many equations during the entropy section it was hard for some students to follow and see when and where to use the equations presented in order to solve problems."

While most of the specific topics had at least one negative response, there was some general agreement about why some topics are not well-suited for the video format. These reasons include the conceptual difficulty of the material, difficulty in understanding the content without examples and mismatch with personal learning style. Two responses illustrate this: "I think topics that are more in-depth and require a lot more thought and time were not suited to the flip lecture"; " [T] he flipped lecture made me familiar with the material, but it didn't teach me enough to be able to, say, take a quiz on it right after. I need to apply the material to homework or practice problems to actually understand the material and know the applicable principles and concepts by intuition." This feedback provides some future direction towards improving the class by modifying videos or switching some topics from video to lecture format.

\section{Confidence and Self-Efficacy}

One of our major questions about the flipped format was whether the students, having completed the course, are confident in their ability to solve problems. Two items address this issue: "I feel confident I can solve problems presented during this course" and "I feel confident I could apply what I have learned in this course to a new problem posed by a future employer." By separating problem-solving in the course from future problem-solving, we consider their reaction to the class itself and their sense of future skill in solving applied thermodynamics problems. Nearly $60 \%$ of respondents agree or strongly agree that they have confidence in solving problems from the class; $79 \%$ agree or strongly agree that they are confident that they will be able to solve future problems (Figure 5.) This is an interesting response; students appear to be more confident and optimistic in approaching new problem posed by a future employer than in solving the problems that they have already attempted during the course. It may be that when students attempted the problems during the class they had incomplete or developing understanding of thermodynamics. Looking forward, the students may be more confident as the result of selfperceived gains in understanding. 


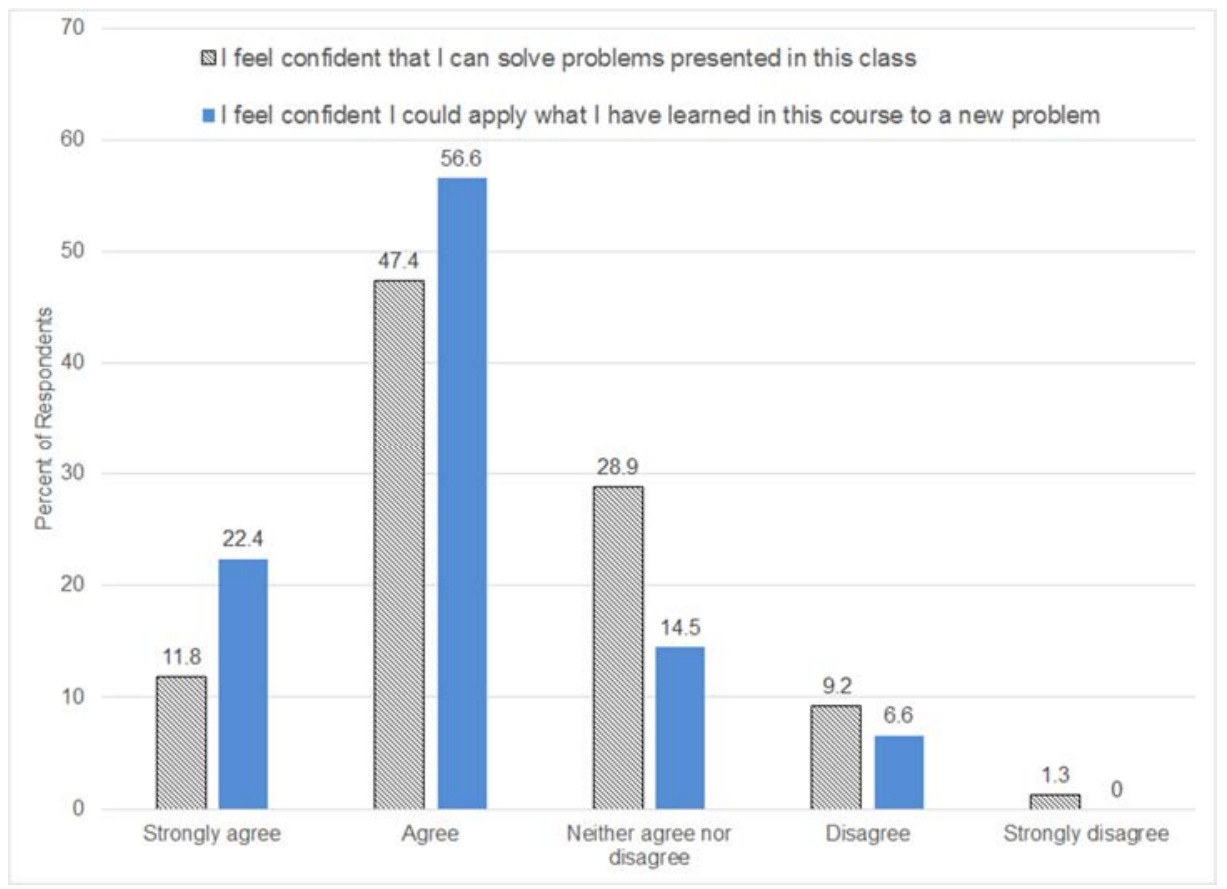

Figure 5. Survey responses: Self-Confidence

Confidence is closely aligned with self-efficacy. Three items on the survey relate to specific aspects of self-efficacy (Figure 6). Student responses to these three self-efficacy items are more mixed than for the self-confidence items although most still agree or strongly agree that the course enhanced their abilities in these areas. The first item asks whether the flipped lecture format helped students to develop their own questions about the material. Since watching videos outside of class and then submitting questions about the videos was a required part of the course, it was a bit surprising that fewer than half of the students agreed or strongly agreed with this statement. The second question asks whether the course format allowed them to develop a deep understanding about the course topics. The responses to this item mirrored those for the first item, with only $46 \%$ agreeing or strongly agreeing. The third item asks if the class helped them to become independent learners. There was more agreement with this item, with $62 \%$ agreeing or strongly agreeing. 


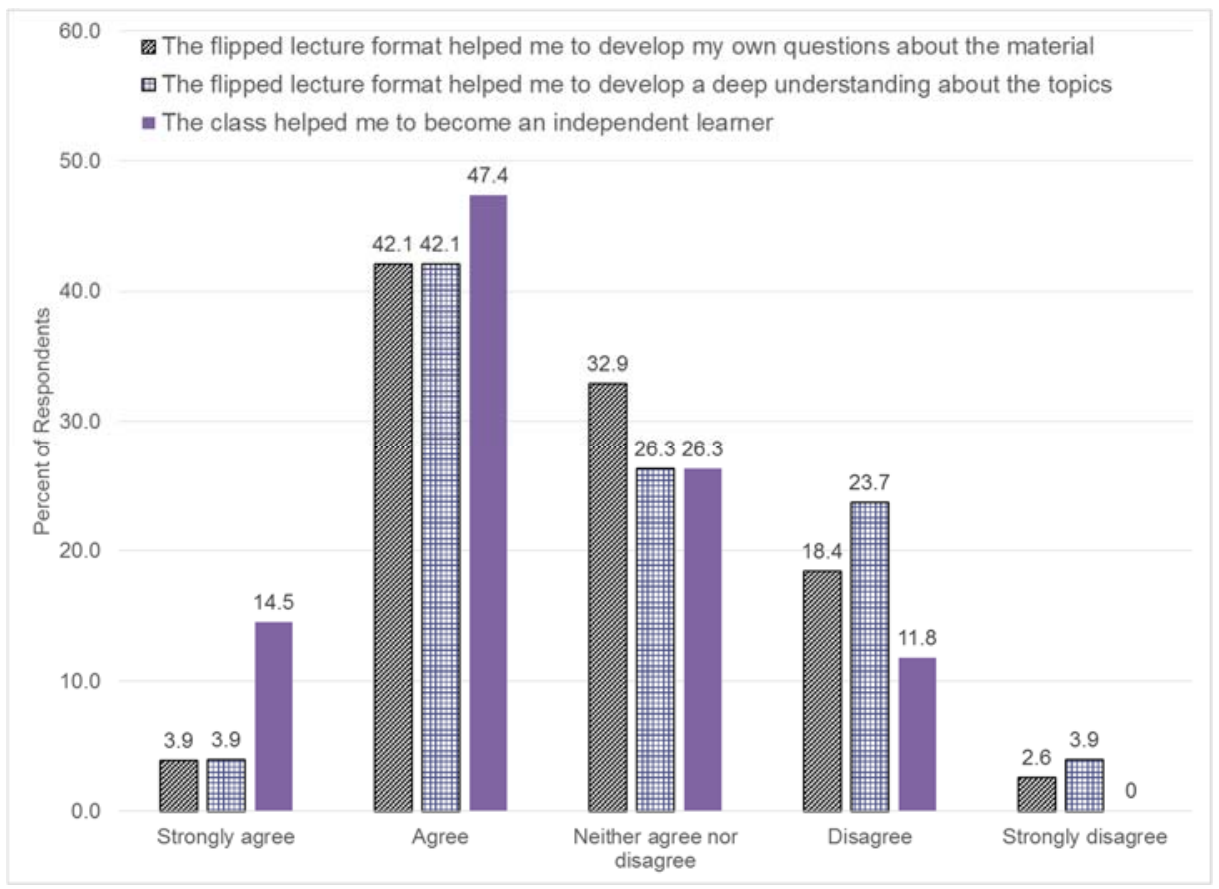

Figure 6. Survey responses: Self-efficacy items

It should also be noted that one of these self-efficacy items refers to the course as a whole and the other two ask specifically about the impact of the flipped lecture format. Without comparison to a non-flipped class, there is not an accurate way to determine if the flipping format improved these outcomes. However, the open-ended responses lend some insight into possible explanations. The two most cited student responses about the impact of watching the videos before class were that they felt more prepared and knew what to expect beforehand which both lead to improved self confidence in the course. One student wrote "I was able to more actively engage in the class because I had a background knowledge of the material. Even though I didn't necessarily fully understand it when I came into class I followed through the lecture better." Another student commented that "I liked knowing what was going to be discussed in class the next day but sometimes the material went over my head until lecture time. At first I did not even know how to formulate questions on what it was I didn't understand (when watching videos), but seeing the material again in class and going over other students questions was very beneficial." An often cited student response was that some videos were hard to follow or too advanced for them. A student that cannot get a basic understanding of the topic will not be able to form their own questions.

Many students also noted that they could not ask questions right away was an issue with the class format. This indicates that they were developing questions on their own but were frustrated with the delay in getting answers. One way to remedy this in the future is to develop a list of commonly asked questions from previous years and make it a companion to the video. Finally, some students were developing their own questions while watching the videos and then researching them outside of class. This suggests that these students are taking advantage of the flipped format to facilitate a deeper understanding of the topic. One such student stated "I have very positive feelings about flip lectures because I can learn at my own pace and research my own questions in as much depth as I care to go. In class I can't always do this because there is 
limited time for discussion." The difference between these two types of responses-frustration versus seeking answers from other sources - may be at least a partial explanation of the mixed response on the questions related to higher cognitive functions associated with the flipped lecture format.

\section{Student grades}

An attempt was made to compare students' final grades (with and without the flip) for three years before flipping the course and three years after. With a comparable number of students (136 students in 2011, 2012, 2013 and 118 students in 2014, 2015, 2016), the grades are statistically the same (mean 2.27 vs 2.26 , standard deviation 0.96 and 0.88 on the 4 point scale). Though using final grades is not a perfect assessment technique, the results were in agreement with results from Bishop (2013), Lape et. al. (2014) and Mason et. al. (2013).

\section{Instructor Observations}

Some of the knowledge gained during the semester was not captured in the surveys or did not relate to the core items asked in the survey but would be useful for anyone wishing to flip a course like this one.

Upon flipping the course, it was evident that students came to class more prepared, with more questions about the content and more motivated to engage in conversation and work out problems. This enthusiasm continued all semester. One often uncited benefit for instructor and student is uniformity in content delivery between multiple sections.

The technique requires a heavy initial investment by the faculty member; every 10 minute video will take 2-3 hours to produce. In creating the videos a few guidelines should be followed or suggested. Create, short concise videos; longer videos were harder for the students to attentively follow and presented a larger investment for them to make outside of class. Production value matters to the students, the instructor has to compete with other sources of information online for student's attention when they are not in the classroom. Tagging, indexing, or organizing content so that students can easily find information is recommended to allow students to review material. Equipment and funding may be available to instructors wishing to implement the technique and should not be overlooked or seen as a barrier.

The instructor investment is not limited to creating the lecture videos, but also includes changing in-class activities. Instructors need additional time and energy for interactive dialogue and problem solving.

The flipped course requirements must be communicated clearly at the beginning of the semester. One student commented "The instructor explained what we had to do in order succeed in this class on the first day of class and then held us to that expectation."

One way of addressing student comments that arose while watching the videos is to provide an outlet for immediate posting of questions, even if they are not answered until class. A discussion board that can be responded to by other students as well as the instructor fits with the model and theory behind flipping the course. Another outlet is to post "commonly asked questions" and the corresponding answers with the videos. 
Finally, by flipping the course after the fourth week, students have already built a relationship with the instructor and the instructor's teaching style even if the lectures are being watched outside of class.

\section{Conclusion}

The results show that students were very satisfied with the way class time was spent in the flipped Thermodynamics course. With flipping, the classroom atmosphere became more relaxed for the students and instructor. The flipped classroom creates an opening to include new activities during class time. In class, this additional time is spent on class discussion and problem solving, which enhances the working relationship created between the student, peers, and instructors as they work collaboratively to solve problems. Students found the flipped class time useful and reported high levels of confidence in their ability to solve related problems in their future academic and professional endeavors. Based on these survey responses, self-efficacy"beliefs in one's capabilities to organize and execute the courses of action required to produce given attainments" - was improved by the course. The benefits of flipping justify the initial instructor's investment.

\section{Acknowledgements}

This work was funded by 4-VA, a collaborative partnership for advancing the Commonwealth of Virginia.

\section{References}

Abeysekera, Lakmal and Dawson, Phillip, "Motivation and cognitive load in the flipped classroom: definition, rationale and a call for research", Higher Education Research \& Development, Vol. 34, No. 1, 1-14, 2015.

Altaii, Karim and Olga Pierrakos, "Flipping Engineering: A Thermodynamics Course Case Study." The Flipped College Classroom: Conceptualized and Re-Conceptualized. Ed. Ross Perkins, Ed. Lucy Santos Green, Ed. Jennifer R. Banas, New York: Springer, Book, 2017.

Bandura, A. Self-efficacy: The Exercise of Control, W.H. Freeman and Company, New York, NY, 1997, p.3

Bishop, Jacob and Verleger, Matthew. "The flipped classroom: A survey of the research." ASEE National Conference Proceedings, Atlanta, GA. Vol. 30. No. 9. 2013.

Bishop, Jacob and Verleger, Matthew, "Testing the flipped classroom with model-eliciting activities and video lectures in a mid-level undergraduate engineering course," 2013 IEEE Frontiers in Education Conference (FIE), Oklahoma City, OK, 2013, pp. 161-163. doi: 10.1109/FIE.2013.6684807

Collins, Allan, Brown, John Seely and Holum, Ann. "Cognitive apprenticeship: Making thinking visible." American educator 15.3 (1991): 6-11. 
Lape, Nancy K., Rachel Levy, D. Yong, K. Haushalter, R. Eddy, and N. Hankel. "Probing the Inverted Classroom: A Controlled Study of Teaching and Learning Outcomes in Undergraduate Engineering and Mathematics." age 24, 2014.

Mason, Gregory, Shuman, Teodora, and Cook, Kathleen, "Comparing the Effectiveness of an Inverted Classroom to a Traditional Classroom in an Upper-Division Engineering Course", IEEE Transactions on Education, Vol. 56, No. 4, 2013.

O'Flaherty, Jacqueline and Phillips, Craig, "The use of flipped classrooms in higher education: A scoping review", Internet and Higher Education, Vol. 25,pp. 85-95, 2015.

Rogoff, Barbara. "Apprenticeship in Thinking: Cognitive Development in Social Context." Oxford University Press. (1991).

Seymour, Elaine, and Hewitt, Nancy M. "Talking about leaving: Why undergraduates leave the sciences, 1997." Boulder, CO: Westview.

Ugursal, V. I., \& Cruickshank, C. A. (2014). Student opinions and perceptions of undergraduate thermodynamics courses in engineering. European Journal of Engineering Education, 1-18.

Wagner, Doug, Laforge, Paul, and Cripps, Douglas, "Lecture Material Retention: a First Trial Report on Flipped Classroom Strategies in Electronic Systems Engineering at the University of Regina", Proc. 2013 Canadian Engineering Education Association (CEEA13) Conf, 2013.

Wessling, F., \& Roller, S. A. (2016, June), "Lessons Learned in Teaching Heat Transfer with a Flipped Classroom." Paper presented at 2016 ASEE Annual Conference \& Exposition, New Orleans, Louisiana. 10.18260/p.25555 